\title{
VARIABILIDADE VERTICAL DE FÓSFORO E POTÁSSIO DISPONÍVEIS E PROFUNDIDADE DE AMOSTRAGEM DO SOLO NO SISTEMA PLANTIO DIRETO ${ }^{1}$
}

\author{
VERTICAL VARIABILITY OF AVAILABLE PHOSPHORUS AND POTASSIUM \\ AND DEPTH OF SOIL SAMPLING IN NO TILLAGE SYSTEM
}

\author{
Jairo André Schlindwein ${ }^{2}$ Ibanor Anghinoni ${ }^{3}$
}

RESUMO

A formação de gradientes dos índices de fertilidade a partir da superfície do solo (variabilidade vertical) gera dificuldades para definir a profundidade de amostragem do solo no sistema plantio direto para representar o seu estado de fertilidade. $O$ estudo visou inicialmente a comparar os rendimentos das culturas nos sistemas plantio avelo $e$ convencional com o mesmo histórico, em diferentes solos e tempo de cultivo e, como houve similaridade, procurou definir a profundidade de amostragem no sistema plantio direto para fins de recomendações de adubação para fósforo e potássio. Para isso, foram selecionados quatro experimentos, conduzidos por longo tempo (10 a 19 anos) nos sistemas convencional e plantio direto, em regióes do estado do Rio Grande do Sul: EEA-UFRGS, em Eldorado do Sul, em Argissolo Vermelho Distrófico; FUNDACEP-FECOTRIGO, em Cruz. Alta, CNPT-EMBRAPA, em Passo Fundo ambos em Latossolo Vermelho Distrófico e, COTRISA, em Santo Angelo em Latossolo Vermelho Distroférrico. Amostras de solo foram, então, retiradas em diferentes camadas a partir da superfície do solo no sistema plantio direto e de $0-20 \mathrm{~cm}$ no sistema convencional. Os teores de fósforo e potássio disponíveis (Mehlich-I) foram um pouco abaixo dos níveis críticos no Argissolo e muito maiores nos Latossolos. $O$ ajuste de profundidade de amostragem foi em torno de $7 \mathrm{~cm} \mathrm{no}$ Argissolo e nos Latossolos; a amostragem em qualquer camada de solo até $20 \mathrm{~cm}$ não altera as recomendações de adubação para os nutrientes estudados.

Palavras-chave: ajuste de calibraçâo, amostragem do solo, sistema plantio direto.

\section{SUMMARY}

The gradient (vertical variability) of soa fertility indexes makes difficult to define lhe depth of soil sampling $m$ the no tillage system to represem the status of soil fertility. The objectives of this study were initially to compare the crop yield in conventional and no tillage systems with some fertilization and crop sequences si different soil and cultivation periods, and as they were similar in yield, to define me depth of soil sampling in the no tillage system for phosphorus and potassium recomendation. Four long-term experiments (10 to 19 years) in conventional and no tillage systems from regions of the state of Rio Grande do Sul - Brazil, were used: EEA-UFRGS, in Eldorado do Sul in a Rhodic Paleudult soil, FUNDACEP-FECOTRIGO, in Cruz Alta, CNPT-EMBRAPA, in Passo Fundo, soils and COTRISA. in Santo Ângelo, all in Rhodic Hapludox soils. Since the crop yields were similar in both tillage systems. soil samples were collected in different layer thickess from lhe sou surface in the no tillage system and in the $0-20 \mathrm{~cm}$ layer in lhe conventional tillage. The phosphorus and potassium content were somewhat below to the criticai leveis for me Paleudult soil and much higher for the Hapludox soils. The adjustement for lhe soil depth is about $7 \mathrm{~cm}$ for lhe Paleudult soil, and in the other soils, with high nutrient content, any soil layer from the soil surface up to around $20 \mathrm{~cm}$ does not affect the fertilizer recommendation.

Key words; calibration adjustment, soil sampling, no tillage

\section{INTRODUÇÃO}

O manejo da fertilidade do solo, envolvendo a aplicação de fertilizantes e corretivos é facilitado no cultivo convencional, pois as operações de preparo do solo promovem a mistura desses insumos com a camada mobilizada de solo. Isso, no entanto, não ocorre no sistema plantio direto, onde a aplicação dos insumos é feita em linhas, na subsuperfície do solo, ou a lanço, na superfície, e a deposição superficial dos resíduos das culturas altera a taxa de decomposição da matéria orgânica e a liberação dos nutrientes na superfície do solo. Isso resulta na formação de gradientes em atributos

\footnotetext{
${ }^{1}$ Parte da Dissertação de Mestrado apresentada pelo primeiro autor à Universidade Federal do Rio Grande do Sul (UFRGS) para obtenção do título de Mestre em Ciência do Solo. Financiado pela FAPERGS e FINEP/PRONEX.

${ }^{2}$ Engenheiro Agrônomo, MSc., Aluno do Curso de Doutorado em Ciência do Solo, PPGA, UFRGS, Av.: Bento Gonçalves, 7712, CP 776, 90001-970, Porto Alegre - RS. E-mail: jairojas@ vortex.ufrgs.br. Autor para correspondência.

${ }^{3}$ Engenheiro Agrônomo, PhD., Professor Adjunto da Faculdade de Agronomia, UFRGS. Bolsista CNPq. 
químicos a partir da superfície do solo, que se intensifica com o tempo de cultivo. Ocorre aumento do teor de matéria orgânica e, conseqüentemente, aumento dos teores de carbono, nitrogénio e capacidade de troca de cátions (ELTZ et al., 1989; SÁ, 1992), formação de uma frente de acidificação (ECKERT, 1991; PAIVA et al., 1996), com aumento dos teores de alumínio trocável e da necessidade de calagem e aumento na concentração de nutrientes, como fósforo, cálcio, magnésio e potássio (ECKERT \& JONHSON, 1985; WEIL et al., 1988; ELTZ et al., 1989; ECKERT, 1991; WIETHÕLTER $\boldsymbol{e}$ t al., 1998). No caso de aplicação superficial de calcário, sem incorporação, ocorre concentração de cálcio e magnésio trocáveis e elevação do pH na superfície do solo.

A formação desses gradientes (variabilidade vertical) gera dificuldades para definir procedimentos de amostragem que refutam o estado de fertilidade do solo. Dessa forma, uma amostra de solo retirada na camada de $0-20 \mathrm{~cm}$ de profundidade, recomendada para o sistema convencional, pode não ser adequada para representar o estado de fertilidade do solo no sistema plantio direto. Por exemplo, a mistura das camadas superiores $(0-2,5$ ou $0-5 \mathrm{~cm})$ com maior teor de fósforo, com camadas inferiores $(15-20 \mathrm{~cm})$ com menor teor, pode determinar um decréscimo proporcionalmente maior nos valores da análise (ANGHINONI \& SALET, 1998). O decréscimo se dá tanto pelo efeito da diluição como pela "fixação" do fósforo em solos com maiores teores de óxidos de ferro e alumínio e em presença de gradiente textural elevado.

As recomendações de adubação, elaboradas regionalmente no Brasil (ANGHINONI \& VOLKWEISS, 1984), foram desenvolvidas para o sistema convencional de manejo, considerando os índices de fertilidade de amostras de solo retiradas na camada mobilizada (arável), normalmente de 0$20 \mathrm{~cm}$. Face às diferenças no manejo e na respectiva variabilidade vertical, especialmente para os nutrientes fósforo e potássio, surgiram muitos questionamentos no meio técnico sobre a necessidade de elaborar recomendações de adubação diferenciadas para o sistema plantio direto (ANGHINONI \& SALET, 1998).

No entanto, devido à similaridade da configuração das curvas de rendimento das culturas nos sistemas plantio direto e convencional, a dinâmica de estabelecimento, os elevados custos e tempo de obtenção das curvas de calibração no sistema plantio direto, levaram à procura de alternativas de ajuste em relação ao sistema convencional, ao invés de construir novas tabelas para o sistema plantio direto. Dentre as alternativas sugeridas (ANGHINONI \& SALET, 1998), o ajuste da profundidade de amostragem, que se baseia na similaridade de rendimento das culturas nos dois sistemas, demonstrada por PETRERE et al. (1996) para diversas situações de solo e culturas no sul do
Brasil, mostrou ser a alternativa mais prática e viável a curto prazo. Essa alternativa é apropriada para o ajuste da recomendação de nutrientes que formam gradientes que decrescem a partir da superfície do solo. Para o ajuste, deve-se determinar a profundidade de amostragem no sistema plantio direto que apresente os mesmos valores dos índices, no caso do fósforo e potássio disponíveis, da camada de $0-20 \mathrm{~cm}$ do sistema convencional, ambos com o mesmo manejo. De posse dos resultados de análise do solo nessa profundidade, pode-se utilizar as tabelas de recomendação de adubação elaboradas no sistema convencional.

Os exemplos de ajuste para esses índices, apresentados por ANGHINONI \& SALET (1998), tiveram mais um valor demonstrativo da metodologia do que propriamente o de uma recomendação de profundidade de uso em geral. Inobstante a isso, e pela necessidade de atender a forte demanda do setor de produção, houve uma recomendação preliminar da Comissão de Fertilidade do Solo do Núcleo Regional Sul da Sociedade Brasileira de Ciência do Solo de coletar amostras de solo na camada de $0-10 \mathrm{~cm}$ no sistema plantio direto consolidado (mais de 5 anos), para servir de base para as recomendações nesse sistema.

Os objetivos deste trabalho foram de comparar os rendimentos de diversas sucessões de culturas com o mesmo histórico de cultivo em diferentes locais, solos, modos de adubação e tempos de cultivo nos sistemas convencional e direto, e no caso de haver similaridade, definir a profundidade de amostragem do solo visando às recomendações de fósforo e potássio no sistema plantio direto.

\section{MATERIAL E MÉTODOS}

Foram utilizados quatro experimentos conduzidos nos sistemas convencional e direto, tendo, cada um deles, o mesmo histórico de cultivo e localizados em diferentes regiões no Estado do Rio Grande do Sul. O primeiro, localizado na Estação Experimental Agronómica (EEA-UFRGS), no município de Eldorado do Sul, região da Depressão Central, foi instalado em 1988, em um Argissolo Vermelho Distrófico típico (EMBRAPA-CNPS. 1999), de textura argila arenosa e substrato granito. Envolve a sucessão aveia preta/milho (Avena strigosa/Zea mays). Coletaram-se, para esse estudo, amostras de solo nas parcelas com adubação a lanço, em ambos os sistemas.

Os dois experimentos seguintes estão localizados na região do Planalto Riograndense, em Latossolo Vermelho típico (EMBRAPA-CNPS, 1999) e substrato basalto. Um deles, localizado na área Experimental da FUNDACEP-FECOTRIGO, em Cruz Alta, foi instalado em 1985, utilizando-se 
neste estudo a sucessão ervilhaca + aveia preta/milho/trigo/soj a/aveia preta/soja (Vicia saliva + Avena strigosa/Zea mays/Triticum aestivum/Glycine mays/Avena strigosa/Glycine mays). Os fertilizantes ( $\mathrm{P}$ e $\mathrm{K}$ ) foram aplicados a lanço. O outro experimento foi instalado em 1984, no Centro Nacional de Pesquisa de Trigo (CNPTEMBRAPA), em Passo Fundo, com a sucessão ervilhaca/milho (Vicia sativa/Zea mays), posteriormente sorgo granífero (Sorgum vulgaré), a partir de 1995, aveia preta/linho (Avena strigosa/Línum ussítatissimum), posteriormente soja (Glycine mays), a partir de 1989 e cevada/soja (Hordeum vulgare/Glycine mays). Os fertilizantes foram aplicados nas linhas de cultivo.

$\mathrm{O}$ quarto experimento foi instalado em 1979 no Centro de Atividades Agrícolas e Florestais da Cooperativa Tritícola de Santo Angelo (COTRISA), em Latossolo Vermelho Distroférrico típico (EMBRAPA-CNPS, 1999), textura muito argilosa, de origem basáltica, localizado na região das Missões, com a sucessão de culturas trigo/soja (Triticum aestivum/Glycine mays). As adubações foram feitas nas linhas de cultivo.

As adubações (N-P-K) nos quatro experimentos foram feitas sempre nas dosagens recomendadas para as culturas utilizadas, conforme a COMISSÃO (1995), a partir das amostras coletadas em camadas com profundidade em tomo de $0-20 \mathrm{~cm}$.

As amostras nos experimentos foram coletadas em maio de 1998, sendo compostas por 45 subamostras simples, conforme determinado em estudo da variabilidade horizontal de atributos de fertilidade e amostragem do solo no sistema plantio direto (SCHLINDWEEN, 1999), de acordo com a equação $n=\left[\left(t \alpha^{*} C V\right) / e\right]^{2}$, com $a=0,05$ e $e$ em relação à média de $10 \%$. As 45 subamostras foram coletadas nas parcelas de plantio direto $\mathrm{e}$ convencional, distribuídas nos blocos de cada experimento. Assim, no caso do experimento ser formado por três blocos, amostraram-se 15 subamostras por parcela em cada bloco. As amostras foram retiradas nas camadas de $0-2,5 ; 0-5 ; 0-7,5 ; 0$ $10 ; 0-12,5 ; 0-15$ e $0-20 \mathrm{~cm}$ de profundidade no sistema plantio direto e de $0-20 \mathrm{~cm}$ no sistema convencional. Nas parcelas com adubação a lanço, coletaram-se amostras com $5 / 10 \mathrm{~cm}$ de espessura/largura, conforme sugerido por SCHLDSTDWEIN et al. (1998). Nas parcelas com adubação em linhas, coletaram-se amostras com $5 \mathrm{~cm}$ de espessura na largura das entrelinhas do último cultivo, de maneira que a linha de cultivo estivesse centralizada na faixa de coleta, conforme recomendado pela COMISSÃO (1995).

As amostras, após secas ao ar e peneiradas, foram analisadas de acordo com os procedimentos descritos por TEDESCO et $\boldsymbol{a l}$. (1995). Determinaram-se os teores de fósforo e potássio disponíveis pelo método Mehlich-I. As análises foram realizadas em duplicata no laboratório, sendo utilizados os dados médios na apresentação dos resultados.

\section{RESULTADOS E DISCUSSÃO}

Os rendimentos das culturas, em longos períodos, com um grande número de safras e/ou cultivos, na média das avaliações no presente trabalho (Tabela 1), não apresentam diferenças consistentes e significativas de um sistema em relação ao outro. Rendimentos maiores (Duncan, $\mathrm{P}<0,05)$ no sistema plantio direto, constatados no experimento localizado na FUNDACEPFECOTRIGO, determinaram, na média da avaliação global, uma certa vantagem, porém não significativa para esse sistema $(4,8 \%)$, sendo semelhante à encontrada (4,2\%) por PETRERE et al. (1996). Os menores rendimentos do sistema convencional na FUNDACEP-FECOTRIGO foram atribuídos por PETRERE et al. (1996) a outros fatores que não ao estado de fertilidade do solo.

Dessa forma, os resultados obtidos nos experimentos utilizados para este estudo, juntamente com os de PETRERE et al. (1996), fornecem o suporte requerido para o ajuste na profundidade de amostragem do solo no sistema plantio direto, como alternativa à construção de novas tabelas de adubação, a partir de novas curvas de calibração ou das demais alternativas apresentadas por ANGHINONI \& SALET (1998).

Para o fósforo e para o potássio, a concentração superficial, com a formação de gradientes devido ao manejo do solo no sistema plantio direto, está caracterizada nas figuras le 2 .

Para o ajuste, determinaram-se, para o sistema plantio direto, equações de regressão quadrática, relacionando as espessuras das camadas de solo a partir da superfície (eixo y) com os respectivos valores dos nutrientes (eixo $\mathrm{x}$ ), para os quatro locais. As equações ajustadas, com as respectivas significâncias, estão apresentadas na figura 1, para fósforo; e na figura 2, para potássio. Para a estimativa da profundidade de amostragem (espessura da camada a partir da superfície do solo) no sistema plantio direto, substituiu-se, em cada equação, o valor de análise do nutriente $(x)$ da camada de $0-20 \mathrm{~cm}$ do sistema convencional e obteve-se, pela resolução da equação, o valor correspondente $(\mathrm{y})$ da profundidade de amostragem no sistema plantio direto. Os valores encontrados foram de 6,$2 ; 23,9 ; 22,4$ e $23,2 \mathrm{~cm}$ para o fósforo e de 7,$7 ; 18,1 ; 20,1$ e $28,6 \mathrm{~cm}$ para potássio, respectivamente nos experimentos localizados na EEA-UFRGS, FUNDACEP-FECOTRIGO, CNPTEMBRAPA E COTRISA.

Apenas no experimento da EEA-UFRGS (Argissolo), a profundidade de ajuste foi próxima dos valores encontrados por ANGHINONI \& 
Tabela 1 - Rendimento módio de diferentes culturas nos sistemas convencional e plantio direto dos experimentos nos difenentes locais e solos

\begin{tabular}{|c|c|c|c|c|c|}
\hline \multirow[b]{2}{*}{ Instituição } & \multirow[b]{2}{*}{ Solo } & \multirow[b]{2}{*}{ Culturas } & \multirow{2}{*}{$\begin{array}{l}\text { Período de } \\
\text { avaliação }\end{array}$} & \multicolumn{2}{|c|}{ Rendimentos médios ${ }^{(1)}$} \\
\hline & & & & $\mathrm{SCO}^{(2)}$ & $\mathrm{SPD}^{(3)}$ \\
\hline & & & Anos - & --.-- kg & $a^{-1} \cdots$ \\
\hline EEA-UFRGS & PVd & $\begin{array}{l}\text { Aveia preta } \\
\text { Milho }\end{array}$ & $\begin{array}{c}8 \\
10\end{array}$ & $\begin{array}{l}4172^{\mathrm{ns}} \\
7239^{\mathrm{ns}}\end{array}$ & $\begin{array}{l}4102^{\text {ns }} \\
7432^{\text {ns }}\end{array}$ \\
\hline \multirow{6}{*}{$\begin{array}{l}\text { FUNDACEP- } \\
\text { FECOTRIGO }\end{array}$} & LVd & Aveia Preta ${ }^{(4)}$ & 1 & 4743 & 4583 \\
\hline & & Aveia + ervilhaca ${ }^{(4)}$ & 1 & 4548 & 4685 \\
\hline & & Trigo & 13 & $2333 \mathrm{~b}$ & $2458 \mathrm{a}$ \\
\hline & & Soja ${ }^{(5)}$ & 13 & $2830 \mathrm{~b}$ & $3129 \mathrm{a}$ \\
\hline & & Soja ${ }^{(6)}$ & 13 & $2798 \mathrm{~b}$ & $3024 a$ \\
\hline & & Milho & 13 & $5366 \mathrm{~b}$ & $6380 a$ \\
\hline \multirow[t]{5}{*}{ CNPT-EMBRAPA } & LVd & Cevada & 14 & $2910^{\mathrm{ns}}$ & $2781^{\text {ns }}$ \\
\hline & & Linho & 5 & $1536^{\text {ns }}$ & $1526^{\mathrm{rs}}$ \\
\hline & & Soja & 13 & $2604^{\text {ns }}$ & $2510^{\mathrm{ns}}$ \\
\hline & & Milho & 3 & $5800^{\text {ns }}$ & $6010^{n+x}$ \\
\hline & & Sorgo & 2 & $7228^{\text {ns }}$ & $7328^{\mathrm{ns}}$ \\
\hline \multirow[t]{3}{*}{ COTRISA } & LVdf & Trigo & 19 & $1504^{\text {ns }}$ & $1326^{\text {ns }}$ \\
\hline & & Soja & 17 & $2170^{n s}$ & $2479^{n s}$ \\
\hline & ' & & & & \\
\hline \multirow[t]{3}{*}{ Mádia ponderada } & \multicolumn{3}{|c|}{ Inverno (61 avaliaçōes) } & $2459^{\text {ss }}$ & $2390^{n s}$ \\
\hline & \multicolumn{3}{|c|}{ Verão (84 avaliaçōes) } & $3785^{\mathrm{ns}}$ & $4104^{\text {ns }}$ \\
\hline & \multicolumn{3}{|c|}{ Inverno e verão (145 avaliações) } & $3227^{\text {ns }}$ & $3383^{\text {ns }}$ \\
\hline
\end{tabular}

Letras diferentes na horizontal diferem estatisticamente pelo teste Duncan, $\mathrm{P}<0,05$ (Segundo o autor: Ruedell, 1995); ${ }^{\text {ns }}$ Teste F (P<0,05), não significativo, utilizando o rendimento médio da cultura de cada ano como repetiçăo; ${ }^{(1)}$ Dados adaptados de Ruedell (1995) e commicação pesscal, Sub-projeto 04.0.94.344.01 do CNPT-EMBRAPA dados não publicados, Dalla Rosa et al. (1981) e comunicação pessoal; (2) SCO = Sistema convencional. ( ${ }^{\text {() }}$ $\mathrm{SPD}=$ Sistema plantio direto. ${ }^{(4)}$ Rendimento de matŕia seca. ${ }^{(5)}$ Soja, no primeino cultivo após o milho. ${ }^{(6)}$ Soja no segundo cultivo após o milho.

SALET (1998), que utilizaram os dados de um experimento de MURDOCK (1985) para fósforo e potássio e do próprio experimento localizado na EEA-UFRGS, para o fósforo, que foram ao redor de $10 \mathrm{~cm}$. A profundidade de ajuste, de $6,2 \mathrm{~cm}$, para fósforo a 7,7cm, para potássio (média 7,0cm), ocorreu no Argissolo, que apresentou os teores próximos dos níveis críticos, e maior (média $22,7 \mathrm{~cm}$ ) nos outros três locais, com solos argilosos (Latossolos) e teores de fósforo e potássio muito acima dos níveis críticos. Estes solos, originalmente, já apresentavam valores acima dos níveis críticos na camada de $0-20 \mathrm{~cm}$ e que, ao longo do tempo (13 a 19 anos), foram sendo fertilizados adequadamente (COMISSÃO, 1995), com intensa reciclagem de nutrientes (ECKERT \& JONHSON, 1985; WEIL $\boldsymbol{e t}$ al., 1988; PAVAN \& CHAVES, 1996; SELLES $\boldsymbol{e} t$ al., 1998) e com perdas desprezíveis por lixiviação e erosão (HERNANI $\boldsymbol{e t} \boldsymbol{a l}$., 1997; SEGANFREDO $\boldsymbol{e} \boldsymbol{t}$ al., 1997), devido ao manejo do solo e de culturas adotado. O não revolvimento do solo no sistema plantio direto, reduz a absorção de fósforo, em relação ao sistema convencional, pela não exposição de novos sítios de absorção (SOUSA \& VOLKWEISS, 1987).

Dessa forma, os teores de fósforo disponível atingiram respectivamente para os diferentes locais, EEA-UFRGS, FUNDACEPFECOTRIGO, CNPT-EMBRAPA e COTRISA, 2,2; 7,9; 12,4 e 14,3 vezes o valor do nível crítico (14 e $6 \mathrm{mg} \mathrm{kg}^{-1}$ no Argissolo e nos Latossolos, respectivamente) na camada de $0-2,5 \mathrm{~cm}$ e de 0,$9 ; 4,3 ; 7,4$ e 6,5 vezes esse valor na camada de $0-20 \mathrm{~cm}$. Da mesma maneira, os teores de potássio disponíveis atingiram respectivamente, para aqueles locais, 1,$7 ; 3,7 ; 5,0$ e 4,6 vezes o valor do nível crítico de $80 \mathrm{mg} \mathrm{kg"'} \mathrm{na} \mathrm{camada} \mathrm{de}$ $0-2,5 \mathrm{~cm}$ e de 1,$0 ; 2,0 ; 2,3$ e 2,7 vezes esse valor na camada de 0-20cm (Figuras $1 \mathrm{e}$ 2).

O solo da EEA-UFRGS (Argissolo) apresenta maior possibilidade de lixiviação de potássio para as camadas mais profundas em relação aos Latossolos e/ou teve maior exportação desse nutriente pêlos grãos em relação à adição pêlos fertilizantes (média $60 \mathrm{~kg} \mathrm{KzO}$ há $^{-1}$ $\mathrm{ano}^{-1}$ ), pois os teores diminuíram, no período, de 132 para $94 \mathrm{mg} \mathrm{kg}^{-1}$, enquanto que, nos Latossolos, os teores aumentaram de 82 para $159 \mathrm{mg} \mathrm{kg}^{-1}$ na FUNDACEP-FECOTRIGO, de 80 para $132 \mathrm{mg} \mathrm{kg}^{-1}$ no CNPT-EMBRAPA e de 98 para $194 \mathrm{mg} \mathrm{kg}^{-1}$ na COTRISA.

Os teores de fósforo disponível aumentaram no período de cultivo no sistema plantio direto em todos os solos. O maior aumento relativo ocorreu no Argissolo, provavelmente devido à característica natural de conter menores teores de óxidos e hidróxidos de ferro e alumínio capazes de adsorver o fósforo inorgânico (ELTZ et al., 1989; ANGHINONI \& SALET, 1998) em relação aos Latossolos.

A amostragem de $0-10 \mathrm{~cm}$ em Latossolo Vermelho Distrófico argiloso cultivado há 13 anos no sistema plantio direto (SÁ, 1995) resultou em coeficientes de correlação superiores em relação à amostragem de $0-20$ e $10-20 \mathrm{~cm}$ na relação de um conjunto de parâmetros de planta (teor de fósforo na folha índice, na matéria seca e no grão e rendimento de milho) com a extração de fósforo do solo por dois métodos (Mehlich-I e Resina). As recomendações de fósforo e potássio, baseadas em amostragem de 0$10 \mathrm{~cm}$, em Latossolo Vermelho Distrófico, há 10 anos nos sistema plantio direto, com níveis adequados desses nutrientes (ESCOSTEGUY et al., 1996), não se diferenciaram das recomendações baseadas na 


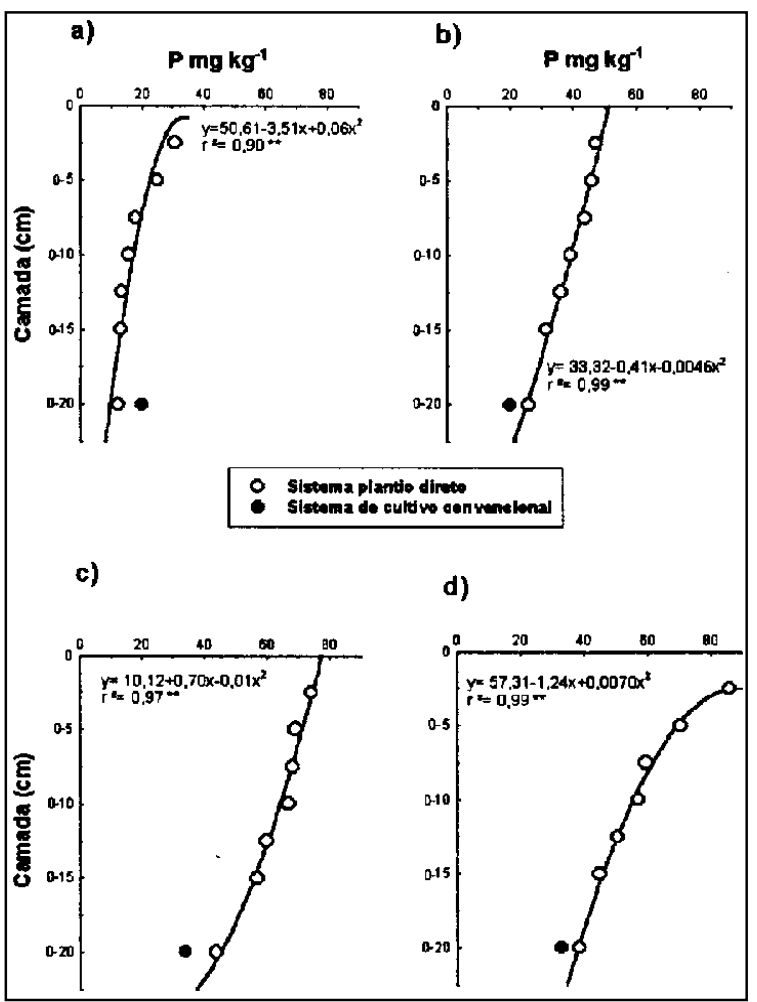

Figura 1 - Teores de fósforo disponível (Mehlich-I) em diferentes camadas a partir da superfície do solo, em diferentes locais e solos. a) Estação Experimental de Agronomia da UFRGS, Eldorado do Sul, RS (PVd); b) FUNDACEP-FECOTRIGO, Cruz Alta, RS (LVd); c) CNPT-EMBRAPA, Passo Fundo, RS (LVd); d) COTRISA, Santo Ângelo, RS (LVdf). **Significado $(\mathrm{P}<0,01)$.

coleta de amostras nas camadas de $0-2,5 ; 0-5,0 ; 10$ 15 e $10-20 \mathrm{~cm}$ ou das médias aritmética e ponderada das camadas de $0-5$ e $5-20 \mathrm{~cm}$. Em todos os casos, os rendimentos de milho não se diferenciaram entre si $(\mathrm{P}<0,05)$.

$\mathrm{O}$ ajuste em profundidade, então, somente se justifica nos casos em que os teores dos nutrientes estiverem abaixo do nível critico. Nos locais onde os teores estão acima dos níveis críticos, a profundidade de amostragem, em qualquer camada da superfície do solo até $20 \mathrm{~cm}$, não altera a recomendação de fertilizantes para as culturas. Quando os teores estão acima do nível crítico, as adubações em superfície têm sido tão eficientes quanto àquelas localizadas nas linhas de adubação (KLEPKER \& ANGHINONI, 1996; WIETHÖLTER et al., 1998). Outros estudos, como o de KLEPKER \& ANGHINONI (1995), mostram que, se parte das raízes estiverem localizadas em frações de solo com teores acima dos níveis críticos, a resposta das culturas dar-se-á em função das mesmas, desde que suficientes para suprir as necessidades das plantas e, ainda, que as condições climáticas sejam favoráveis. É lógico pensar que a camada superior do solo $(0-10 \mathrm{~cm})$, a qual concentra a

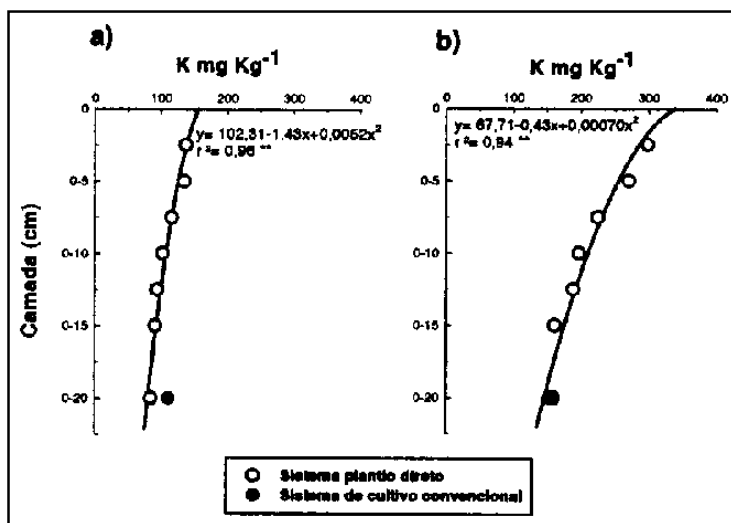

c)

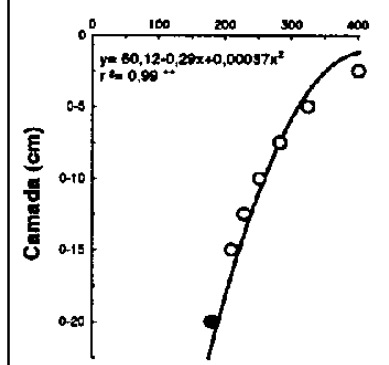

d)

Figura 2 - Teores de potássio disponível (Mehlich-I) em diferentes camadas a partir da superfície do solo, em diferentes locais e solos. a) Estação Experimental de Agronomia da UFRGS, Eldorado do Sul, RS (PVd); b) FUNDACEP-FECOTIRIGO, Cruz Alta, RS (LVd); c) CNPT-EMBRAPA, Passo Fundo, RS (LVd); d) COTRISA, Santo Ângelo, RS (LVdf).

maior quantidade de raízes e com maior capacidade de absorção dos nutrientes, nas quais determina a performance das plantas.

Nas condições nas quais a fertilidade do solo está acima dos níveis críticos, pode ser recomendada a utilização das tabelas do sistema convencional, para a fertilização das culturas no sistema plantio direto. $O$ que recomenda, nessa situação, é apenas a quantidade de manutenção, ou poderia ser utilizado, opcionalmente a essa, e dependendo do valor da análise, a quantidade de reposição calculada pela exportação dos grãos ou forragem, com análises periódicas para monitorar o estado de fertilidade do solo.

A profundidade de amostragem em tomo de $0-10 \mathrm{~cm}$, encontrada em trabalhos de demonstração da metodologia de ajuste por ANGHINONI \& SALET (1998), foi sugerida para uso geral pela Comissão de Fertilidade do Solo NRS/SBCS, em 1998. Entretanto, os resultados do presente trabalho indicam a necessidade de utilizar experimentos com teores de fósforo e potássio disponíveis abaixo da faixa suficiente (nível crítico), para maior conhecimento da variabilidade vertical do solo, em diferentes condições de manejo da 
fertilidade e assim definir a melhor maneira de representar o real estado de fertilidade dos mesmos.

\section{CONCLUSÕES}

O rendimento das culturas é similar nos sistemas convencional e de plantio direto em áreas submetidas ao mesmo manejo de culturas e doses de fertilizantes, desde que as perdas de solo sejam desprezíveis. Ocorre formação de gradientes dos índices de fósforo e potássio disponíveis, a partir da superfície do solo no sistema plantio direto; a magnitude desses índices varia com o solo e com o respectivo manejo. $\mathrm{O}$ ajuste de profundidade de amostragem, para fins de recomendação de fósforo e potássio no sistema plantio direto, justifica-se somente quando o solo apresenta teores desses nutrientes abaixo dos níveis críticos, situando-se, o ajuste, em tomo de $7 \mathrm{~cm}$; acima dos níveis críticos, a amostragem, em qualquer profundidade até $20 \mathrm{~cm}$, não altera as recomendações de adubação.

\section{AGRADECIMENTOS}

Aos pesquisadores José Ruedell e Ciro Petrere da FUNDACEP-FECOTRIGO, José Denardin e Rainoldo Alberto Kochhann do CNPT-EMBRAPA e Amando Dália Rosa e João Becker da COTRKA, por disponibilizar as áreas experimentais para a coleta das amostras e por fornecer as informações sobre o histórico das mesmas e os resultados de rendimento das culturas.

\section{REFERÊNCIAS BIBLIOGRÁFICAS}

ANGHINONI, I., SALET, R.L. Amostragem do solo e as recomendações de adubação e calagem no sistema plantio direto. to: NUERNBERG, N. J., (ed.). Conceitos e fundamentos do sistema plantio direto. Lages : Núcleo Regional Sul/SBCS, 1998. p.27-52.

ANGHINONI, I., VOLKWEISS, S.J. Recomendações de uso de fertilizantes no Brasil, to: ESPINOSA, W., OLIVEIRA, A.J. Anais do Simpósio na Agricultura Brasileira. Brasília : EMBRAPA-DEP, 1984. p.179-204.

COMISSÃO DE FERTILIDADE DO SOLO - RS/SC. Recomendações de adubação e calagem para os estados do Rio Grande do Sul e Santa Catarina. 3 ed. Passo Fundo : SBCS - Núcleo Regional Sul, 1995. 224p

DALLA ROSA, A., MERTEN, G.H., MIELNICZUK, J. Produtividade do trigo e da soja em sistemas de culturas e preparo do solo. Trigo e Soja, Porto Alegre, v.1 13, p.1418,1991 .

ECKERT, D.J. Chemical atributes of soils subjected to no tillage cropping with rye cover crop. Soil Sei Soe Am J, Madison, v.77, n.789-792,1991.

ECKERT, D.J, JOHNSON, J.W. Phosphorus fertilization in no tillage com prodution. Agr J, Madison, v.77, n.789-792,1985.

ELTZ, F.L.P., PEIXOTO, R.T.G, JASTER F. Efeitos de sistemas de preparo do solo nas propriedades físicas e químicas de um latossolo bruno álico. R Brás Ci Solo, Campinas, n.13, p.259 267,1989 .
EMBRAPA-CNPS. Sistema Brasileiro de Classificação de Solos. Rio de Janeiro: EMBRAPA-CNPS, 1999. 412p,

ESCOSTEGUY, P.A.V., BRUGNERA, A., ARGENTA, G., et al. Profundidade de amostragem de solo e resposta à adubação com NPK na cultura do milho, cultivada no sistema plantio direto. to: REUNIÃO SUL BRASILEIRA DE CIÊNCIA DO SOLO, 1996, Lages, SC. Resumos expandidos... Lages : NRS/SBCS, 1996. 166p. p.22-24.

HERNANI, L.C-, SALTON, J.C., FABRICIO, L.C, et al. Perdas por erosão e rendimentos de soja e de trigo em diferentes sistemas de preparo de um latossolo roxo de Domados (MS). R Brás Ci Solo, Campinas, n.21, p.667-676,1997.

KLEPKER, D., ANGHINONI, I. Crescimento radicular e aéreo do milho em vasos em função do nível de fósforo no solo e da localização do adubo fosfatado. R Brás Ci Solo, Campinas, v. 19, p.403-408,1995.

KLEPKER, D., ANGHINONI, I. Modos de adubação, absorção de nutrientes e rendimento de milho em diferentes preparos de solo. Pesq Agr Gaúcha, Porto Alegre, n.2, p.79-86,1996.

MURDOCK, L. Soil Sampling for no-till: how different is it? Better Crops With Plant Food, Atlanta, n.69, p.21-23,1985.

PAIVA, P.J.R., VALE, F.R.do, FURTINI NETO, A.E., et $\boldsymbol{a l}$. Acidificação de um latossolo roxo do estado do Paraná sob diferentes sistemas de manejo. R Brás Ci Solo, Campinas, n.20, p.20-71,1996

PAVAN, M.A., CHAVES, J.C.D. Alterações nas frações de fósforo no solo associadas com a densidade populacional de cafeeiros. R Brás Ci Solo, Campinas, n.20, p.251-256,1996.

PETRERE, C., SALET, R.L., ANGHINONI, I. Produtividade de culturas nos sistemas plantio direto e convencional no sul do Brasil, to: REUNIÃO SUL BRASILEIRA DE CIÊNCIA DO SOLO, 1996, Lages, SC. Resumos expandidos. Lages : NRS/SBCS, 1996. 166p. p.74-76.

RUEDELL, J. Plantio direto na região de Cruz Alta. Cruz Alta : FUNDACEP/FECOTRIGO, 1995. 134p.

SÁ, J.C.M. Manejo da fertilidade do solo no sistema plantio direto. Castro-PR: Fundação ABC, 1992. 57p.

SÁ, J.C.M. Manejo do fósforo no sistema plantio direto. ta: SEMINÁRIO INTERNACIONAL DO SISTEMA PLANTIO DIRETO, 1995, Passo Fundo. Resumos expandidos. Passo Fundo: EMBRAPA-CNPT, 1995. 181p. p.83-99.

SEGANFREDO, ML, ELTZ, F.L.F, BRUM, A.C.R de. Peidas de solo, água e nutrientes por erosão em sistemas de culturas em plantio direto. RBrasCS Solo, Campinas, n.21, p.287291,1997

SELlES, F., KOCHHANN, R.A., DENARDDM, J.E-, $\boldsymbol{e} \boldsymbol{t} \boldsymbol{a l}$. Distribuition of phosphorus in a Brazilian oxisol under different tiliage systems. Soil \& Tülage Research, Amsterdam, n.44, p.23-34,1998.

SCHLINDWEIN, J.A., SALET, R.L., ANGHINONI, I. Variabilidade dos índices de fertilidade do solo no sistema plantio direto e coleta de amostras representativas de solo. ta: REUNIÃO BRASILEIRA DE FERTILIDADE E NUTRIÇÃO DE PLANTAS, 23; REUNIÃO BRASILEIRA SOBRE MICORREAS, 7; SIMPÓSIO BRASILEIRO SOBRE MICROBIOLOGIA DO SOLO, 5; REUNIÃO BRASILEIRA DE BIOLOGIA DO SOLO. 1998, Caxambu, MG. Resumos... Caxambu :Fertibio 98,1998. 863p. P.265. 
SCHUNDWEIN. J.A. Variabilidade da fertíüdade e amosiragem do solo no astenia plantio direto. Porto Alegre, RS, 1999. HOp. Dissertação (Mestrado em Ciência do Solo) - Curso de Pós-graduação em Ciência do Solo, Univeisidade Federal do Rio Grande do Sul, Porto Alegre, 1999.

SOUSA, D.G.M., VOLKWEISS, S.J. Efeito residual do superfosfato triplo aplicado em pó e em grânulos. R Brás Cl Solo, Campinas, n.1l, p.141-146,1987.

TEDESCO, M.J., GIANELlO, C., BISSANI, C.A., et al. Análise de solo, plantas e outros materiais. 2 ed. Porto Alegre :
Departamento de Solos da Faculdade de Agronomia da UFRGS, 1995. 147p. (Boletim Técnico, n.5)

WEIL, R.R., BENEDETTO, P.W., SDÍORA, LJ., et al Influence of tiliage practices on phosphorus distribuidon and forms and three ultisols. AgrJ,Madison,n.80,p.503-509,1988.

WIETHÖLTER, S., BEN, J.R., KOCHHANN, R., et aí Fósforo e potássio no solo no sistema plantio direto. h: NUERNBERG, N. J. (ed.). Conceitos e fundamentos do sistema plantio direto. Lages: Núcleo Regional Sul/SBCS, 1998. p.121-149.

Ciência Rural, v. 30, n. 4, 2000. 